\title{
JOB SATISFACTION OF OCCUPATIONAL MEDICINE NURSES IN POLAND
}

\section{PIOTR SAKOWSKI}

\author{
Nofer Institute of Occupational Medicine, Łódź, Poland \\ Organization and Management in Health Care Unit, Health Policy Department
}

\begin{abstract}
Objectives: The study aimed at assessment of the Polish occupational medicine service system after over ten years of functioning in the current shape, made by occupational nurses. The article focuses on the job satisfaction level among Polish occupational medicine nurses. Materials and Methods: The survey was performed among 600 randomly selected occupational medicine nurses, registered in the regional occupational medicine centers. A questionnaire, designed by the research team, containing several questions concerning different aspects of OMS system assessment, including a part dedicated to job satisfaction assessment, was sent to the selected occupational nurses. The response rate was $33.3 \%$ (200 questionnaires). Results: The survey shows a relatively high satisfaction level in case of five out of eleven investigated job aspects, and a very low satisfaction level in case of two of them ("Possibility of professional promotion", "Salary"). $26 \%$ of the OMS nurses had considered going abroad to work as a nurse in the general health care system, and $17 \%$ in the OHS system. Almost $25 \%$ of them would not choose a profession of an occupational nurse once again, including $10 \%$ who would not choose a nurse job at all. There is a statistically significant correlation between the general job satisfaction and satisfaction with other aspects of nursing work. A strong correlation was observed in case of "Scope of performed tasks" and "Cooperation with employers (clients of the occupational medicine service units)". There is a statistically significant correlation of average strength between the decision concerning choosing an occupational nurse job in case of taking a decision on professional carrier once again and "General job satisfaction". Conclusion: Polish occupational nurses are satisfied with their job, however only $26 \%$ are fully satisfied. In their work there is place for improvement. The areas which definitely need attention and improvement are "Possibility of professional promotion" and "Salary". Improvements in cooperation between occupational nurses and physicians can make it close to the best practice.
\end{abstract}

Key words:

Job satisfaction, Occupational nurse, Nursing, Occupational health

\section{INTRODUCTION}

One of the goals of the study was to learn about the job satisfaction level among Polish occupational medicine nurses. Job satisfaction of occupational nurses has been for a long time a forgotten area in the Polish research. The Polish occupational medicine system in its current shape has been functioning since 1998, having as its most important legal basis the provisions of the Occupational
Medicine Service Act [1]. In brief, in this Act, there are clearly described duties of occupational medicine service (OMS). The provisions concerning the tasks of occupational nurses may be found in the Act [1] and one of its executive ordinances [2] (note: at the time of writing this paper this ordinance [2] became recognized as ineffective and its new version is expected to be published). A significant element in the Polish OMS system are its

The study has been carried out under the project IMP 8.2/2009 "Occupational health protection system in Poland in the opinion of occupational nurses, in particular their role, tasks and utilization of professional skills".

Received: May 25, 2011. Accepted: November 17, 2011.

Address reprint request to P. Sakowski, Organization and Management in Health Care Unit, Health Policy Department, Nofer Institute of Occupational Medicine, św. Teresy 8, 91-348 Łódź, Poland (e-mail: psak@imp.lodz.pl). 
organizational units: the primary OMS units, and regional occupational medicine centers (ROMC), which may be regarded as organizations (some of them smaller, some bigger) forming a part of the bigger system. Taking into account the fact that the organization itself is some kind of a system [3] and that it produces an outcome, it is very important to have tools for outcome assessment. From the patient's point of view, undoubtedly, one of the important issues is nursing quality. Many surveys show that job satisfaction is a very important nursing quality outcome indicator [4-7]. The study aimed at general assessment of the Polish OMS system after over ten years of its functioning in the current shape, made by occupational nurses. This article continues the subject matter undertaken in the previous publication [8], and this time it focuses on occupational nurses' job satisfaction aspects.

\section{MATERIALS AND METHODS}

The survey was performed in a randomly selected group of 600 occupational medicine nurses, registered in the regional occupational medicine centers. This number makes approximately $10 \%$ of all occupational nurses registered in Poland (there is no national, country-wide, official register, thus the total number of occupational nurses was a value estimated on the basis of the available data). A questionnaire, designed by the research team, taking into account special characteristics of the occupational nurses practice, containing several questions concerning different aspects of the OMS system assessment, including a part dedicated to job satisfaction assessment, was sent to selected occupational nurses. The response rate was 33.3\% (200 questionnaires). Although this rate might not be regarded as high enough in the general population, the research team treats it as sufficient for the purposes of this study, as the study concerns a rather homogenous group of medical professionals with a similar level of education, range of duties, similar responsibility, common interest, or general objectives of the whole professional group.

\section{RESULTS}

The mean age of nurses participating in the survey was 49.3 years ( standard deviation $=8.4$; median $=50$; mode $=53$ ). The mean up-to-date time of employment as a nurse was 28 years (standard deviation $=8.8$; median $=30 ;$ mode $=30$ ), and as an occupational nurse -16 years $($ standard deviation $=10$; median $=13$; mode $=10$ ). The majority of the nurses worked in the primary occupational medicine units (almost 67\%, $\mathrm{N}=189$ ), a minority - in ROMC (16.4\%) and other facilities outside the OMS system (17\%). They worked most frequently in non-public health care units $(39.3 \%, \mathrm{~N}=196)$, with a smaller proportion employed in public units $(31.1 \%)$. The third kind of units mentioned by the interviewees was an individual nurse practice (22.4\%), and the remaining ones (above 7\%) included an individual physician practice, a group physician practice and a group nurse practice. $14 \%$ of the questioned nurses ( $N=195)$ had higher education and the title of a master's degree or a bachelor's degree in nursing.

The research team asked them for the assessment of the satisfaction level in ten different aspects of the performed job and the assessment of "General job satisfaction". The distribution of responses to that question is contained in Table 1. The level of satisfaction was assessed in a fourgrade scale (explanation under Table 1).

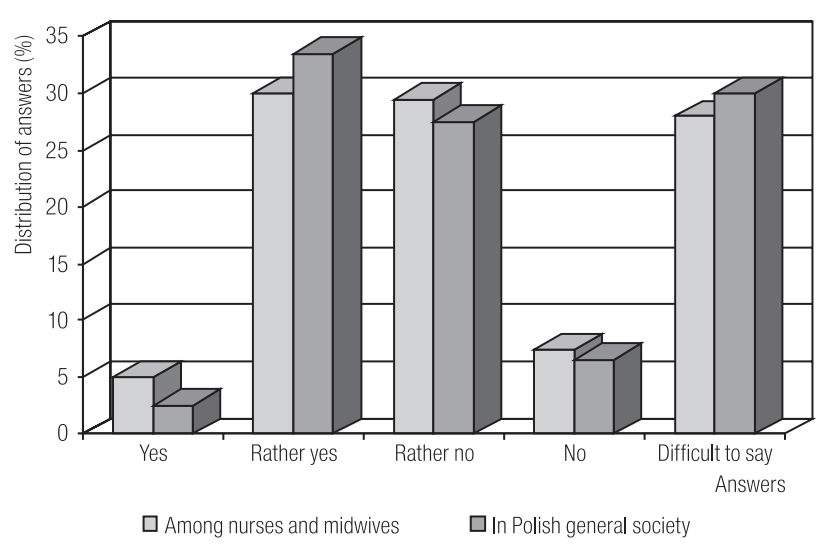

Fig. 1. Distribution of answers to the question: "Do you think that occupational medicine nurses enjoy high prestige among nurses and midwives and in the general Polish society?" $(\mathrm{N}=200)$ 
Table 1. Job satisfaction among occupational nurses - assessment of different job aspects and general satisfaction

\begin{tabular}{|c|c|c|c|c|c|c|c|c|}
\hline \multirow{2}{*}{ Item } & \multirow{2}{*}{ Job aspects } & \multirow{2}{*}{$\mathrm{N}(100 \%)$} & \multicolumn{4}{|c|}{ Satisfaction level $(\%)^{*}$} & \multirow{2}{*}{$\begin{array}{l}\text { Mean } \\
\text { value }\end{array}$} & \multirow{2}{*}{$\mathrm{SD}^{* *}$} \\
\hline & & & 1 & 2 & 3 & 4 & & \\
\hline 1 & Scope of performed tasks & 195 & 3.1 & 10.8 & 57.9 & 28.2 & 3.11 & 0.85 \\
\hline 2 & Cooperation with occupational physicians & 197 & 5.6 & 8.6 & 50.2 & 35.6 & 3.16 & 0.88 \\
\hline 3 & $\begin{array}{l}\text { Cooperation with other professionals } \\
\text { (e.g. psychologists, ergonomists) }\end{array}$ & 190 & 23.2 & 18.4 & 35.2 & 23.2 & 2.58 & 1.20 \\
\hline 4 & $\begin{array}{l}\text { Cooperation with employers (clients of } \\
\text { occupational medicine service units) }\end{array}$ & 198 & 14.1 & 21.2 & 45.5 & 19.2 & 2.70 & 0.97 \\
\hline 5 & Cooperation with employees (patients) & 198 & 3.0 & 7.6 & 51.0 & 38.4 & 3.25 & 0.79 \\
\hline 6 & Responsibility for undertaken activities & 197 & 1.5 & 9.1 & 45.2 & 44.2 & 3.32 & 0.81 \\
\hline 7 & Prestige of an occupational nurse profession & 197 & 9.1 & 23.4 & 43.1 & 24.4 & 2.83 & 0.96 \\
\hline 8 & Salary & 198 & 46.0 & 25.2 & 21.7 & 7.1 & 1.90 & 0.99 \\
\hline 9 & $\begin{array}{l}\text { Possibility of knowledge and skills } \\
\text { advancement }\end{array}$ & 197 & 12.6 & 17.7 & 48.0 & 21.7 & 2.78 & 0.96 \\
\hline 10 & Possibility of professional promotion & 189 & 46.6 & 22.7 & 23.3 & 7.4 & 1.92 & 1.06 \\
\hline 11 & General job satisfaction & 198 & 1.0 & 13.6 & 59.1 & 26.3 & 3.11 & 0.72 \\
\hline
\end{tabular}

* Satisfaction level was assessed in a four-grade scale: 1 - I am totally dissatisfied; 2 - I am dissatisfied, but I can notice some advantages; 3 - I am satisfied, but I can notice some disadvantages; 4 - I am fully satisfied.

** SD - standard deviation.

One of the assessed aspects was "Prestige of an occupational nurse job". The nurses were asked for their opinion concerning their perception of the prestige among two populations: nurses and midwives and the Polish general society. The results are shown in Figure 1.

Although the answers were distributed almost equally between "yes" and "no" options, the self-assessment of being satisfied with "Prestige of an occupational nurse profession" showed that many of the responding nurses are not satisfied with the prestige of their profession.

The nurses were also asked if they had ever considered a possibility of working abroad as a nurse - either in general health care or in occupational health care. The results show that every fourth nurse had considered going abroad to work as a nurse in the general health care system, and almost every sixth of them would take a job in the occupational health care system (Figures 2 and 3). The combined results of those two questions show that $14 \%$ of occupational nurses had considered going abroad to work as a nurse both in OHS and/or general health care (56\% of those who had been thinking about the possibility of going abroad to undertake work as a nurse in the general health care system in a different country and $82 \%$ of those who had been thinking about the possibility of going abroad to undertake work as a nurse in the occupational health service in a different country; $\mathrm{N}=194$ ). Among the responding nurses, 29\% (including the already mentioned 14\%) had considered a possibility of going abroad to work as a nurse taking into account all the three possibilities: in the general health care system, in the occupational health service and both in general health care and/or OHS.

One of the questions in the questionnaire concerned the choice of an occupational nurse job in case of taking a decision on the professional carrier once again. Three out of four interviewees would choose an occupational nurse job once again. However, almost $25 \%$ of them would not 


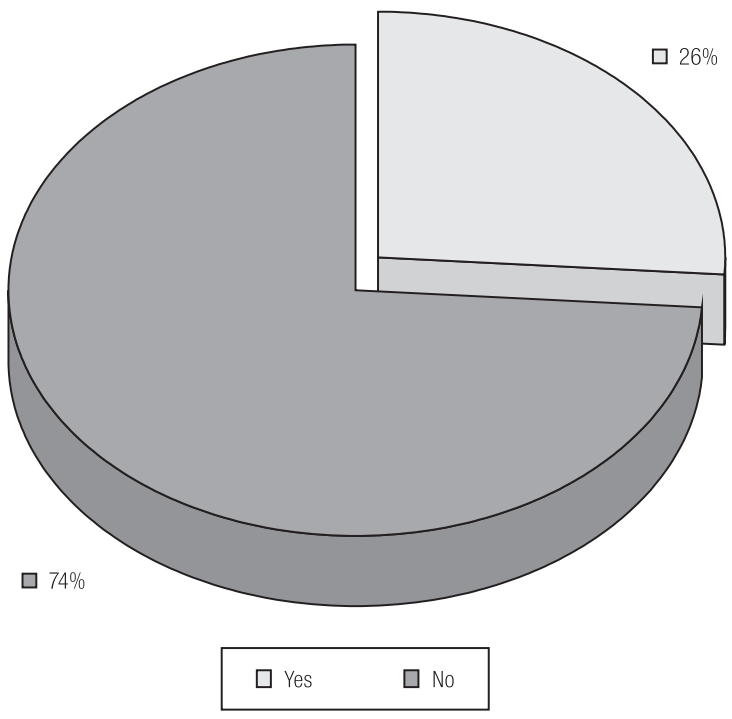

Fig. 2. Distribution of answers to the question concerning thinking about the possibility of going abroad to undertake work as a nurse in the general health care system in a different country $(\mathrm{N}=198)$

do so, and moreover, one in ten would not choose a nurse job at all (of any specialization). More details - contained in Figure 4.

Further statistical analysis and calculations of chi square showed that a null hypothesis may be rejected and the differences between satisfaction with different job aspects are not caused by a random distribution of the sample ( $\alpha=0.001$, with exception of "Salary" having $\alpha=0.01$ ). There is a statistically significant correlation between the general job satisfaction level and satisfaction with other aspects of nursing work. A strong correlation was observed in case of "Scope of performed tasks" (Pearson's correlation coefficient $r=0.51$ ) and "Cooperation with employers (clients of occupational medicine service units)" with $r=0.54$. A correlation of average strength was observed in case of "Cooperation with occupational physicians", "Cooperation with other professionals (e.g. psychologists, ergonomists)", "Cooperation with employees (patients)", and "Prestige of an occupational nurse profession" with the $r$ value varying from 0.32 to 0.4 . A correlation with other aspects may be described as weak, where the weakest

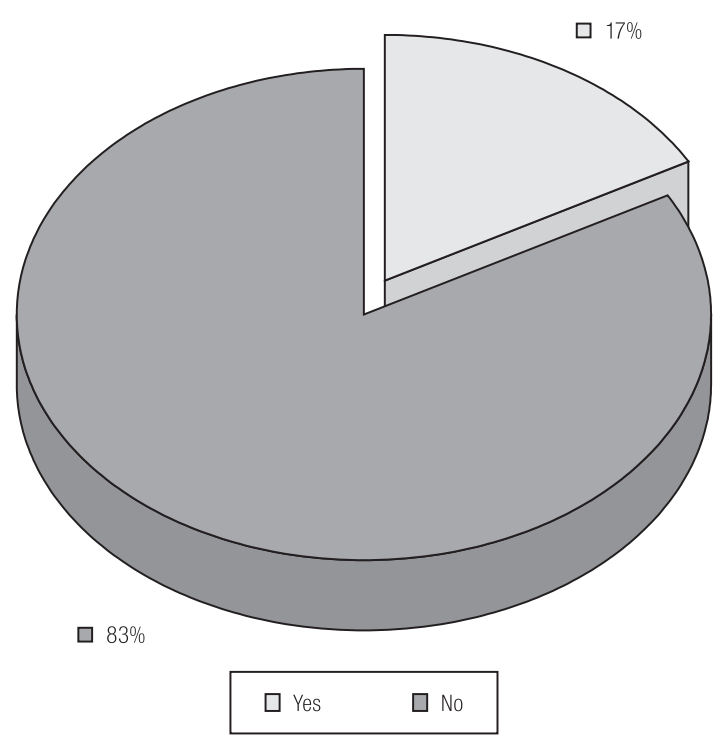

Fig. 3. Distribution of answers to the question concerning thinking about the possibility of going abroad to undertake work as a nurse in the occupational health service in a different country $(\mathrm{N}=194)$

one was in case of the aspect of "Salary". Detailed results are contained in Table 2.

In addition, the survey showed a very weak correlation between "General job satisfaction" and considering the possibility of going abroad to work as a nurse in the OHS system



Fig. 4. Distribution of decisions concerning choosing an occupational nurse job in case of taking the decision about professional carrier once again $(\mathrm{N}=199)$ 
Table 2. Correlations between "General job satisfaction" and other aspects of job satisfaction

\begin{tabular}{lrrrr}
\hline \multirow{2}{*}{\multicolumn{1}{c}{ Aspects of job satisfaction }} & \multicolumn{3}{c}{ General job satisfaction } \\
\cline { 2 - 5 } & chi ${ }^{2}$ & $\alpha$ & $\begin{array}{c}\text { two-tailed } \\
\text { p-value }\end{array}$ & $\mathrm{r}^{*}$ \\
\hline Scope of performed tasks & 51.01 & 0.001 & $<0.0001$ & 0.51 \\
Cooperation with occupational physicians & 28.82 & 0.001 & $<0.0001$ & 0.40 \\
Cooperation with other professionals (e.g. psychologists, ergonomists) & 18.68 & 0.001 & $<0.0001$ & 0.32 \\
Cooperation with employers (clients of occupational medicine service units) & 24.16 & 0.001 & $<0.0001$ & 0.54 \\
Cooperation with employees (patients) & 20.18 & 0.001 & $<0.0001$ & 0.32 \\
Responsibility for undertaken activities & 14.68 & 0.001 & 0.0001 & 0.18 \\
Prestige of an occupational nurse profession & 24.83 & 0.001 & $<0.0001$ & 0.36 \\
Salary & 7.84 & 0.010 & 0.0051 & 0.15 \\
Possibility of knowledge and skills advancement & 12.85 & 0.001 & 0.0003 & 0.26 \\
Possibility of professional promotion & 14.58 & 0.001 & 0.0001 & 0.28 \\
\hline
\end{tabular}

* Pearson's correlation coefficient.

Table 3. Correlations between a decision concerning choosing an occupational nurse job in case of taking the decision about professional carrier once again and different aspects of job satisfaction (only statistically significant)

\begin{tabular}{|c|c|c|c|c|}
\hline \multirow{2}{*}{ Aspects of job satisfaction } & \multicolumn{4}{|c|}{$\begin{array}{l}\text { Decision concerning choosing an occupational nurse job in case } \\
\text { of taking the decision about professional carrier once again }\end{array}$} \\
\hline & $\operatorname{chi}^{2}$ & $\alpha$ & $\begin{array}{l}\text { Two-tailed } \\
\text { p-value }\end{array}$ & $\mathrm{r}^{*}$ \\
\hline $\begin{array}{l}\text { Cooperation with employers (clients of occupational } \\
\text { medicine service units) }\end{array}$ & 6.69 & 0.010 & 0.0097 & 0.18 \\
\hline Prestige of an occupational nurse profession & 11.1 & 0.001 & $<0.0001$ & 0.24 \\
\hline Salary & 8.77 & 0.010 & 0.0031 & 0.19 \\
\hline Possibility of professional promotion & 7.79 & 0.010 & 0.0053 & 0.20 \\
\hline General job satisfaction & 22.06 & 0.001 & $<0.0001$ & 0.33 \\
\hline
\end{tabular}

* Pearson's correlation coefficient

$\left(\right.$ chi $^{2}=5.49 ; \alpha=0.02 ;$ two-tailed $\mathrm{p}$-value $=0.0191 ;$ $\mathrm{r}=0.16)$, and tenure in OMS $\left(\mathrm{chi}^{2}=6.76 ; \alpha=0.01\right.$; twotailed $\mathrm{p}$-value $=0.0093 ; \mathrm{r}=0.19)$. A similar correlation was observed in case of satisfaction with "Salary" and considering the possibility of going abroad to work as a nurse in the OHS system $\left(\right.$ chi $^{2}=5.49 ; \alpha=0.02$; two-tailed $\mathrm{p}$-value $=0.0191 ; \mathrm{r}=0.17)$.

There is a statistically significant correlation between the decision concerning choosing an occupational nurse job in case of taking the decision on the professional career once again and five of eleven aspects of job satisfaction. The correlations are shown in Table 3.

\section{DISCUSSION}

Occupational nurses in Poland are in general a quite experienced professional group. The survey shows that they usually work for some time as a nurse and then they take 
a decision about working in occupational health care. An obvious benefit resulting from this fact for the OMS system is having in its structures highly skilled staff with several years of practice. The majority of the OMS units in Poland are the primary units, which was reflected in the survey.

The survey shows relatively high general job satisfaction among Polish occupational nurses, and also a quite high level of satisfaction regarding four other studied aspects:

- Responsibility for undertaken activities,

- Cooperation with employees (patients),

- Cooperation with occupational physicians,

- Scope of performed tasks.

The areas, where the satisfaction level was rather low were:

- Prestige of an occupational nurse profession,

- Possibility of knowledge and skills advancement,

- Cooperation with employers (clients of occupational medicine service units),

- Cooperation with other professionals (e.g. psychologists, ergonomists).

Special attention should be paid to those aspects where the satisfaction level was very low:

- Possibility of professional promotion,

- Salary.

Although satisfaction with "Cooperation with occupational physicians" was assessed quite high, in the opinion of the research team it is worth noticing that almost $15 \%$ of the nurses were not satisfied with this aspect, and additionally - over $50 \%$ could notice some disadvantages in this field. Taking into account that proper cooperation between the two most numerous professional groups within the OMS system is one of the preconditions of good service quality, those figures should be an incentive for further improvement of such cooperation, making it close to the best practice.

There were noted mixed opinions about „Prestige of an occupational nurse job”, which cannot lead to clear conclusions. Almost equal numbers of answers confirmed and denied that this job is perceived as prestigious both among the nurses and midwives population and the general Polish population. However, self-assessment of satisfaction with "Prestige of an occupational nurse profession" showed that many of the respondents were not satisfied with the prestige of their profession.

There was an interesting observation made in scope of the subjects thinking about going abroad to work as a nurse. $26 \%$ of the OMS nurses had considered going abroad to work as a nurse in the general health care system, and $17 \%$ in the OHS system. Furthermore, going deeper into the analysis, $14 \%$ of the nurses would take a nurse job in another country both in OHS and/or in general health care. In addition, almost $25 \%$ of the nurses would not choose an occupational nurse job once again, including $10 \%$ who would not choose a nurse job at all. Those results, confronted with the results of the general indicator of job satisfaction showing that more than $85 \%$ of the questioned nurses were satisfied with their job, may suggest that there are some factors that might influence the nurses' willingness to continue their professional career, especially in the conditions found in Poland. A statistical analysis showed that there is a statistically significant correlation between the decision concerning choosing an occupational nurse job in case of taking the decision on the professional career once again and five out of eleven aspects of job satisfaction, which are: satisfaction with "Cooperation with employers (clients of occupational medicine service units)", satisfaction with "Prestige of an occupational nurse profession", satisfaction with "Salary", "Possibility of professional promotion" and "General job satisfaction". There was another interesting observation noted - as many as four out of those five aspects were connected with a low satisfaction level among the responding nurses. As a result, this may possibly lead to a conclusion that the reason for not choosing an occupational nurse job again by almost $25 \%$ of the respondents lies within those 
four fields (one or, more probably, more than one): "Cooperation with employers", "Prestige of an occupational nurse profession", "Salary", and "Possibility of professional promotion".

According to the best knowledge of the research team, this study was probably the first one in our country that assessed job satisfaction among Polish occupational nurses after 1998, and there is no comparable data available in literature databases relating to this field of medicine in Poland. There are of course other studies of nurses' job satisfaction, however in different specializations. Demographic data shows that occupational nurses (mean age 49.3 years) are an older group than the general population of nurses in Poland (mean age 42.3) [9]. According to the data of the Central Statistical Office, 5.1\% of all nurses have a master's in nursing [10], which is a little higher result than that among occupational nurses - this survey revealed $4.6 \%$ of occupational nurses with a master's degree in nursing (with additional $9.7 \%$ with a bachelor's degree in nursing, giving the total of $14.3 \%$ of occupational nurses with higher education). The results of this survey in the area of "General job satisfaction" (a quite high level) stay in some opposition to the findings of Walas et al. [11] who assumes community/family nurses work satisfaction at an average level, and they show a higher level of general job satisfaction than the findings of Zajkowska and Marcinowicz, simultaneously having similar observations concerning satisfaction with "Salary" [12] among the primary care nurses in Poland. An international literature review concerning job satisfaction among nurses [13] shows that "Salary" and "Job promotion" are often important factors and they also are on dissatisfying level, which confirms the findings of this survey. However, those issues are likely to vary in different countries, due to different organization and economic situation of health care systems. According to Zajkowska and Marcinowicz [12], nurses from the USA seem to be much more content with their salaries than Polish nurses. The results obtained by Kunecka [14] also show high percentages of nurses dissatisfied with their salary $(54.7 \%)$ and possibility of promotion $(24.8 \%)$.

\section{CONCLUSIONS}

The completed survey has made it possible to come to a few conclusions that reflect the situation in the Polish occupational medicine system in relation to occupational nurses job satisfaction. Despite some limitations of the survey (e.g. not very big response rate), it shows some important contemporary trends.

The Polish occupational nurses in general are satisfied with their job, however only $26 \%$ are fully satisfied. Thus, in the occupational nurses' work there is still place for improvement, and to make this work better it is necessary to focus on those areas in which the drawbacks are visible. The areas where the level of satisfaction is very low and which therefore need special attention and improvement are first of all "Possibility of professional promotion" and "Salary".

Furthermore, among the aspects marked with the low satisfaction level is cooperation both with employers (clients of OMS) and other professionals (except physicians), which may suggest that the theoretical assumption of OMS being a multidisciplinary service is not very well realized in real life. In addition, there was observed a rather low level of satisfaction in the field of possibilities of advancement of nurses' knowledge and skills, which shows that there are shortages in this important area of professional development and it may be the factor that could influence the quality of the whole OMS in Poland (well-skilled and educated staff should be regarded as a precondition of a well-functioning system). Moreover, low satisfaction in the area of "Prestige of an occupational nurse profession", combined with very low satisfaction with "Possibility of professional promotion" and "Salary" might possibly result in the future - in case of no improvements in those areas - in growing dissatisfaction and frustration among 
Polish occupational nurses and their outflow from the profession, as well as a decreased inflow of new occupational nurses in case of popularization of the negative images or drawbacks of the profession among nurses and young people who are making their first steps on their professional road and having to decide about their future job and/or specialization.

Finally - to finish with a little more positive issue - taking into account that proper cooperation between occupational nurses and physicians is one of the preconditions of good service quality, although the survey showed a quite high level of satisfaction with this aspect among nurses, the results of the study should become an incentive for further improvement of such cooperation, making it close to the best practice.

\section{REFERENCES}

1. Occupational Medicine Service Act of 27 June 1997. Off J 1996, No. 96 pos. 593 with amendments [in Polish].

2. Ordinance of the Minister of Health and Social Protection of 15 September 1997 concerning tasks of occupational medicine service of which performing by nurses requires additional qualifications, kind and mode of acquiring those qualifications and kinds of documents confirming them. Off J 1997, No. 124, pos. 796 [in Polish].

3. Koźmiński AK, Piotrowski W, eds. Management. Theory and Practice. Warszawa: Wydawnictwo Naukowe PWN; 2000. p. 30 [in Polish].

4. Tzeng HM, Ketefian S. The Relationship between Nurses' Job Satisfaction and Inpatient Satisfaction: An Exploratory Study in a Taiwan Teaching Hospital. J Nurs Care Qual 2002;16(2): 39-49.
5. Tzeng HM, Ketefian S, Redman RW. Relationship of nurses' assessment of organizational culture, job satisfaction, and patient satisfaction with nursing care. Int J Nurs Stud 2002;39: 79-84.

6. American Nurses Association. Nursing report card for acute care. Washington, DC: ANA; 1995.

7. Szecsenyi J, Goetz K, Campbell S, Broge B, Reuschenbach $\mathrm{B}$, Wensing $\mathrm{M}$. Is the job satisfaction of primary care team members associated with patient satisfaction? BMJ Qual Saf 2011;20:508-14. DOI: 10.1136/bmjqs.2009.038166.

8. Sakowski P. Self-assessment of tasks and roles of occupational medicine service (OMS) nurses in the polish system of workers' health Protection. Med Pr 2010;61(5):561-72 [in Polish].

9. Main Chamber of Nurses and Midwives. Analysis of an age structure of registered nurses and midwives acquiring right to retirement pension. Warsaw; 2007 [cited 2011 May 12]. Available from URL: http://www.izbapiel.org.pl/upload/Analiza_ wrzesien_2007.pdf [in Polish].

10. Table 2 (270). Medical personnel (as of 31.XII). In: Statistical Yearbook of the Republic of Poland 2010. Vol. LXX. Warszawa: Central Statistical Office; 2010. p. 407

11. Walas L, Kachaniuk H, Kusiak L, Fidecki W, Sadurska A, Wysokiński M, et al. Professional satisfaction range of community/family nurses. Zdr Publ 2007;117(1):32-5.

12. Zajkowska E, Marcinowicz L. Elements of professional satisfaction among nurses of primary health care in Poland and the United States. Zdr Publ 2005;115(3):274-8 [in Polish].

13. Lu H, While AE, Barriball KL. Job satisfaction among nurses: a literature review. Int J Nurs Stud 2005;42:211-27. DOI: 10.1016/j.jijnurstu.2004.09.003.

14. Kunecka D. Employee's satisfaction and medical service quality. Probl Hig Epidemiol 2010;91(3):451-7 [in Polish].

This work is available in Open Access model and licensed under a Creative Commons Attribution-NonCommercial 3.0 Poland License - http://creativecommons.org/ licenses/by-nc/3.0/pl/deed.en. 